\title{
Basic train control system for regional branch lines - field test report
}

\author{
B. Stadlmann \\ University of Applied Sciences Upper Austria, Wels, \\ School of Engineering and Environmental Sciences, Austria
}

\begin{abstract}
This paper presents a new kind of train control system for branch lines which are operated by radio-based operational train control. Most branch lines with such operating limitations cannot afford the cost of investment for modern signalling systems. The train control system presented herein represents a low cost solution which improves safety, increases ease of operation, and introduces an interesting level of automation without any costly line-side installations. It is based on data radio communication between the central computer, which is located in the dispatcher's office and trains (each train is equipped with an on-board computer), cab signalling in the trains, and autonomous determination of train location using GPS and an odometer. Low cost has been achieved by using standard industrial computer hardware within the trains and by omitting any line-side installations, such as signals. Safety has been achieved by special operational sequences and by software redundancy. In Austria this system is in full operation on several lines (standard as well as narrow gauge) with a total length of appr. $90 \mathrm{~km}$.
\end{abstract}

Keywords: train control system, GPS based train location, operational train control, regional branch line, operational train control.

\section{Introduction}

This paper presents a train control system which has been developed at the Upper Austrian University of Applied Sciences in Wels. The paper presents the motivation for the development, and presents the system with its components, its safety aspects, its possibilities for automation and the operational experiences. 


\section{The train control system}

\subsection{Background of the train control system}

Regional branch lines are very often operated using the radio-based operational train control (German: Zugleitbetrieb mit Sprechfunk). The single-track line traffic controller gives the movement authority to the train driver via radio phone. (e.g.: Train $\mathrm{x}$ has movement authority until A-stop where it will cross paths with train y). The movement authority will be marked in a graph of train running. Principles are explained in more detail in [1] and [2].

Using this kind of operating principle the standard of safety is poor. An error on the part of one single person could result in a severe accident. Numerous accidents in the past have shown this risk. In Austria three accidents happened in 2002 and 2004. On the Danube riverside line the train dispatcher sent two overlapping movement authorities to the trains, which then crashed into one another. On the Mur valley line and on the line from Lambach to Vorchdorf the given movement authorities were correct but one of the train drivers did not wait for the oncoming train at the crossing station, which yielded a similar outcome.

It is obvious that safety must be improved. Many regional branch lines can not afford the investment costs for electronic switching and standard signalling systems.

\subsection{Basic idea of the train control system}

The basic idea of the train control system is to leave the operational principle as it is, but provide support for it by using a computer system. The train controller performs the same sequences as before, now using a screen, mouse and a data radio system instead of pencil and radio-based oral communication.

To achieve a low cost solution redundant hardware has been dropped and line-side installations have been reduced to a minimum. The only line-side installation is the data radio system. The crossing stations are equipped with spring switches to facilitate crossing without the use of an electronic signal box. Movement authorities are displayed to the train driver in the cab.

The basic concept of the train control system is depicted in Figure 1.

\section{Technical description}

\subsection{Overview}

The system consists of three main elements: (1) One on-board computer in each train, (2) the data radio system for communication (3) the central computer for the train controller. All safety relevant actions within the computer-based train control system require the explicit input of the train operator or the engine driver.

\subsection{On-board computer}

The on-board computer consists of an appropriate industrial PC with I/Omodules and interfaces running an Ada-multitasking-application under the 


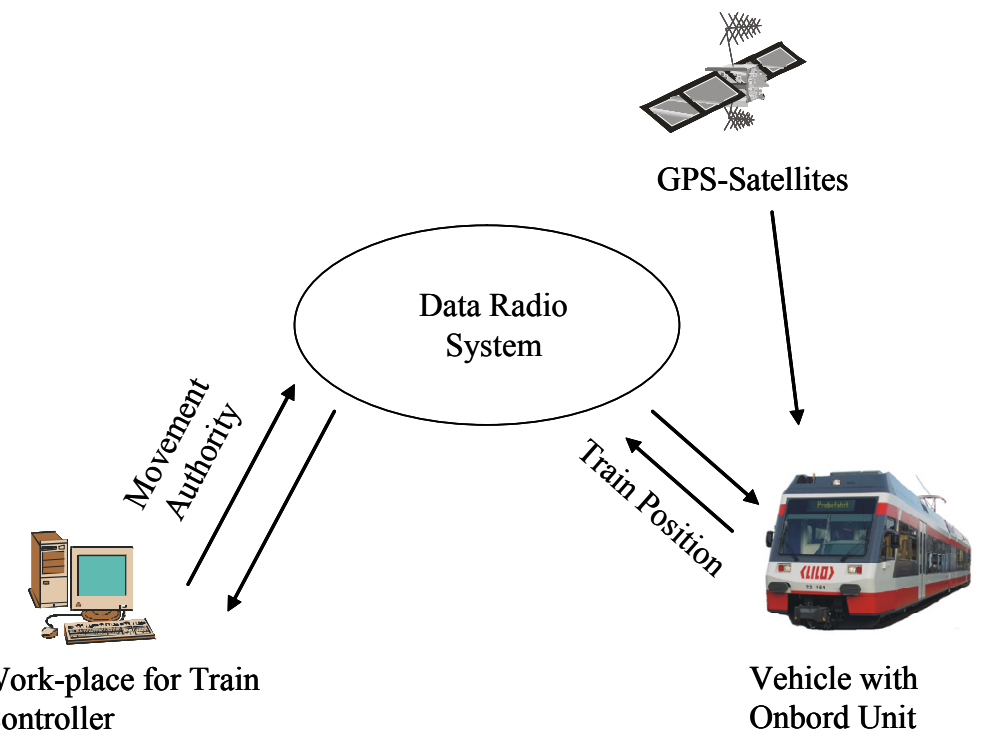

Figure 1: Schematic functionality of the train control system.

operating system ETS. It is responsible for the following tasks: (1) Train location is determined using GPS data and an incremental sensor at one axle. Both of them are used to supervise and complement each other. The result is matched with the line data from the digital line atlas to get a position using line-based coordinates. The incremental encoder is used to measure the speed and the relative position of the train during normal operation, while the GPS data provides a point of reference and acts as a supervision and backup system. (2) Data communication between the train and the central computer is performed and supervised. (3) Visualisation and communication to the engine driver (HMI) via a terminal, which is frequently refreshed by a mirrored virtual screen within the computer. This mirrored virtual screen is likewise protected by a CRCchecksum. An example of a modern car equipped with the new terminal for cab signalling is depicted in Figure 2. (4) All received movement authorities are thus visualized and their accuracy duly supervised (see chapter 4.2) (5) Electronic protocolling of selected driver's actions is written to a memory flash card. (6) Data for dynamic passenger information in the train may be obtained from the on-board computer. (7) Time and date are synchronised between all computers.

\subsection{Data radio system}

The communication between trains and the central device is performed by a linespecific data radio system using a radio frequency within the 2 meter band. This data radio system is equipped with high level roaming and easy-to-install repeaters. Typically there is a need for one base station per $10 \mathrm{~km}$ line, which can be situated on the roof of a station building or at another similar site. No other line-side equipment has to be installed. 


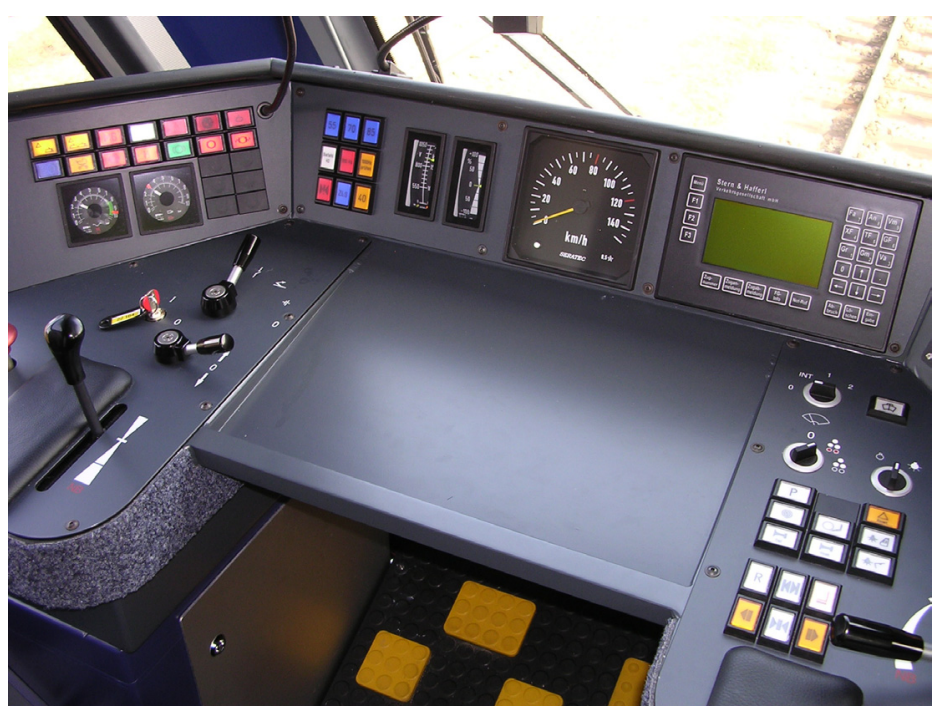

Figure 2: $\quad$ Engine driver's place with the screen of the train control system for cab signalling (right of the tachometer).

Safety of the data transmission is very high. Data telegrams use two different $\mathrm{CRC}$-checksums for data integrity and a sequence number to determine double and lost telegrams. Due to the checksums the remaining failure rate is less then $10^{-10}$

\subsection{Central computer}

The central computer uses normal server hardware and runs under the operating system Windows. It consists of a core application, implemented as an Ada-application, and a GUI for visualisation, which has been implemented as a Java-application. The communication between these two parts runs over TCP/IP.

The core application is responsible for the following basic tasks: (1) Registering the trains dynamically as they enter the area of the train control system. (2) Registering all movement authorities as they are keyed in by the train controller and accepted by the on-board computer and the engine driver. They are then deleted when the train reports having left the related section of the line. This report is based on the automatic train location in combination with the manual confirmation of the engine driver. (3) Maintaining communication to the trains via the data radio system. (4) Transmitting the received RTCM correction data from a stationary GPS-receiver to the trains. (5) Electronic protocolling of all data traffic via radio and all user inputs.

As a background safety measure, a special task has been implemented within the core application which monitors the distance between trains. If this distance reaches a lower limit, the task will trigger an alarm in both trains to execute an emergency stop. This "lower limit" is calculated as the sum of the braking 
distances of the two trains moving towards each other and the distance travelled before and after fault detection (taking into account the time for data transmission).

Within the visualisation part (GUI) two different representations of the line are available: (1) On the one hand there is a schematic presentation of the line and its tracks, where the trains are represented by rectangular symbols. (2) On the other hand there is a scaled electronic train diagram including theoretical as well as actual train running representing the trains as dots.

Both presentations are available simultaneously on screen at the central computer (see Figure 3). The visualisation of the movement authorities and the train locations are available in both presentations, each in a different manner.

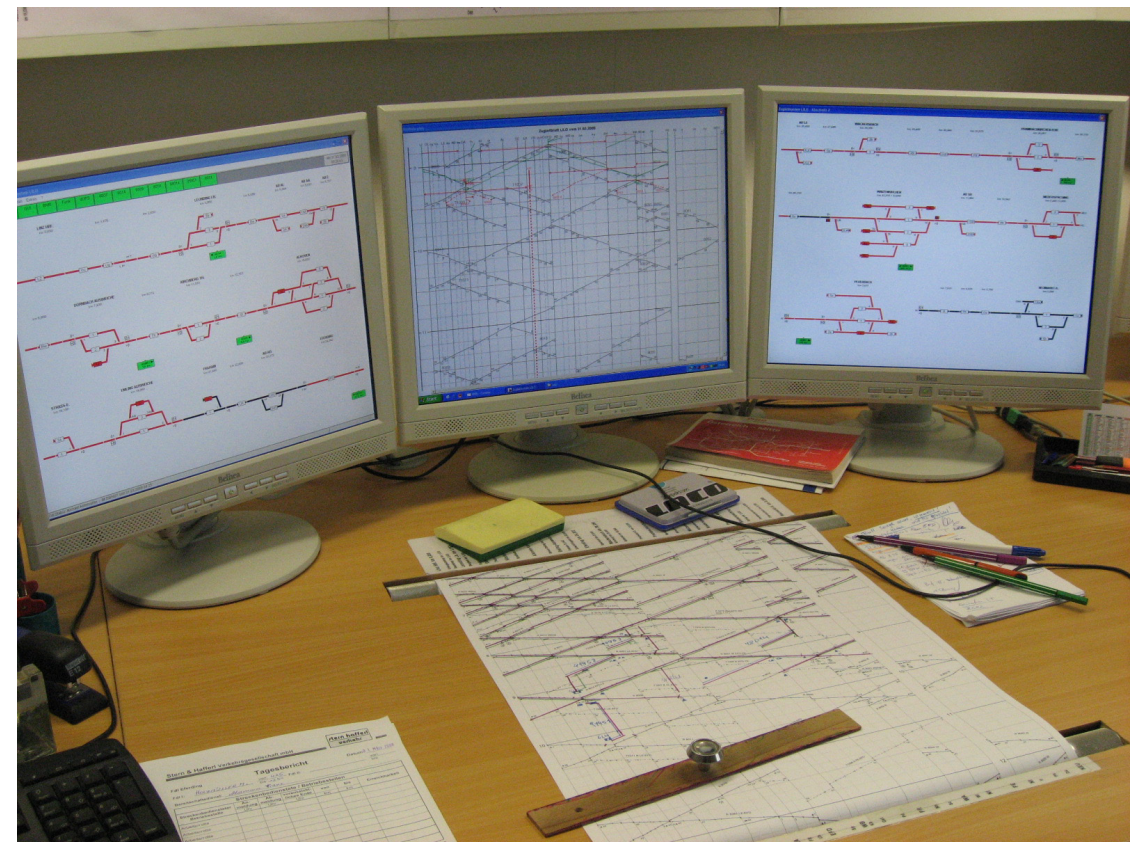

Figure 3: The train controller's view on the screens of the central computer. The middle screen depicts the scaled electronic train diagram.

The supervision of the system by the operational staff is supported by the permanent visualisation of all relevant system states including an appropriate failure management system.

This failure management system consists of two elements: (1) For the train driver there are only 2 warning steps. The first step is the request to check the calculated train position manually. The second step is the request to switch off the system and to proceed using oral communication as a backup level. (2) For the train controller there are pre-determined error messages for each train (e.g. "location of the train not safe", "train is running without movement 
authority") and for the central computer. Therefore the train controller can easily decide how to react accordingly.

\section{Safety}

\subsection{Safety policy}

Safety of the train control system is based on a combination of numerous redundancies within the software and operational sequences combining plausibility checks executed by the software and the controlling inputs of the operators, the train controller and the train driver.

The safety of the GPS-based train location is also important for the system safety, but system safety of the train control system is not based on the train location alone as mentioned before.

The software development process has been organised in a simplified manner analogous to the requirements of EN 50128 [3]. A detailed description of the system requirements was the first step of this design process. An overview of the UML-based design process of this project can be found in [4].

\subsection{Resulting safety features}

There are a couple of special safety features: (1) Emergency brake for an arbitrary train, (2) no train movement without an movement authority, (3) collision avoidance alarm, (4) supervision of the correct execution of the movement authority.

The train controller may initiate an emergency brake at any time to any train. This command is sent to the train and activates the emergency brake without an action of the train driver.

The train may not be moved without an adequate movement authority. If there is an attempt to move the train, an automatic emergency brake is performed. The train driver might overrule this feature using a special command key. The use of this command key is protocolled electronically.

The collision avoidance alarm is a special feature of the central computer which is an additional safety feature highly independent of all other algorithms as mentioned in chapter 3.4 .

The correct execution of the movement authority is supervised in three steps as shown in Figure 4.

\section{Interoperability, automation and interfaces}

\subsection{Interoperability}

Interoperability is an important goal for any European standard gauge line. The train control system presented in this paper can be made interoperable using a mobile unit for guest engines. This mobile unit (see Figure 5) is housed in a 


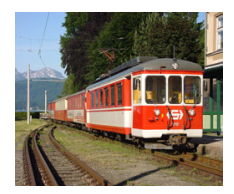

movement authority

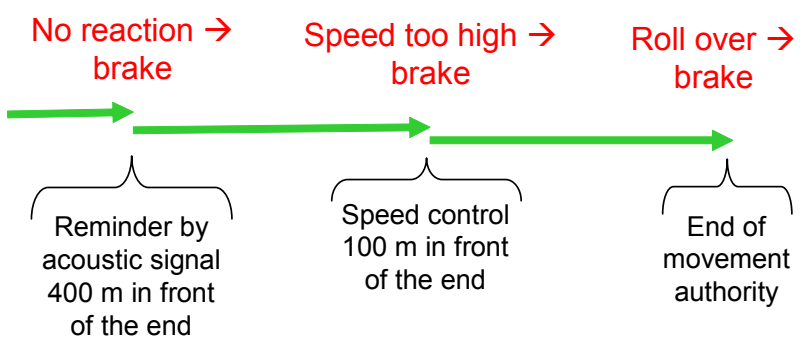

Figure 4: Supervision of the correct execution of the movement authority within three steps.

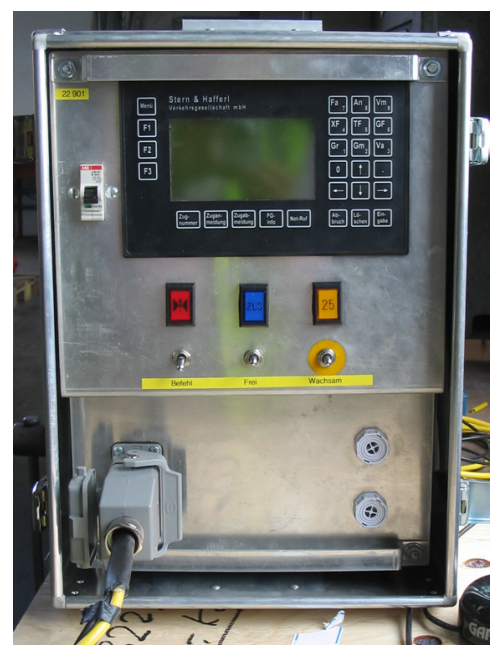

Figure 5: Mobile unit of the on-board computer for temporary use in any engine.

portable box which can be put in the driver's cab of any engine. The mobile unit only needs $24 \mathrm{~V}$ from the power supply. All antennas can be fixed magnetically outside the cab.

These mobile units are also used for a couple of engines which are rarely used like special maintenance engines or nostalgic trains.

\subsection{Automation and operational interfaces}

The train control system with its computer based support would enable one train controller to control several distributed regional branch lines simultaneously especially during times of day when traffic is low. 
The widespread computer based support for the operational train control has lead to an even simpler mode of operation. One train controller can supervise more trains (even on several different lines) at the same time which leads to a reduction of personnel cost. The operational commands to the trains are delivered quicker and with less chance of being missunderstood than when communicated orally.

Though the train control system is intended for stand-alone operation, on certain branch lines it has been adapted with technical interfaces to standard signalling systems in the train as well as the operational interfaces between the operational train control and the major lines with standard signalling. That means trains from the branch line can enter the signalling area of a major line and vice versa, using well defined procedures.

\subsection{Dynamic passenger information}

The train control system is used as a basis for the data for dynamic passenger information at the stations and within the web. In order to fulfil these requirements the central computer sends appropriate messages with the actual running data to the dynamic passenger information server.

\subsection{Additional useful features}

Based on the existing features of train location and data communication some very useful features have been implemented easily. (1) An automatic alarm has been implemented, so that the operator on duty is alarmed by mobile phone in the event of a technical alarm within the engine. This feature is in operation around the clock. (2) Regional branch lines often have low-radius curves, which can lead to the problem of squeaking. The train control system now controls the precise (precise in the sense of an exact location) emission of a special lubrication for the rails to reduce this noise which is very irritating for the neighbouring population. (3) Within the stops the moveable tread is controlled depending of the height of the platform.

\section{Final approval}

As there had been no previous examples of this kind of train control system this project has required close cooperation with experts from the Austrian federal Ministry of Transportation.. After two years of testing the running system the Ministry of Transportation nominated two external experts for the expert review. One of these was to examine the operational reliability of the train control system while the second expert was to verify the technical documentation and technical safety of the system.

During the review process further improvements were made to the system based on the recommendations of the experts. In cooperation with the experts the amount of final documentation was also defined. The expert's report for the operational evaluation [5] states that the technical system combined with the operational principles provides a sound basis for the safe operation. This is 
attributable to the combination of different plausibility checks and the automatic and manual operational sequences of the train control system.

An additional practical test for the insulation of the data radio antenna and the GPS device with regard to high voltage strength had to be taken in consideration. Though these devices have been in operation on electrically operated railway vehicles for many years, no adequate certificate could be presented by the manufacturers. The goal of this test was to determine whether a person inside the vehicle is in danger if a high voltage overhead wire were to fall on top of the antennas.

After meeting all of the necessary requirements, final approval for the train control system was given in 2006 .

\section{Experience}

\subsection{Comparison of cost}

The low investment costs compared to standard signalling systems are a big advantage of the train control system. Even compared to simplified standard signalling systems, the cost for the train control system are appr. $10 \%$ to $20 \%$ of a simplified standard signalling system due to the lack of line-side installations. This figure was the result of a couple of comparable offers for two specific regional branch lines.

\subsection{Experience of operation}

The period of test operation which was necessary to obtain final approval and in order to optimise the system lasted three years. Since then train control system has been in full operation for more than two years on about $90 \mathrm{~km}$ of single track lines. There is a daily number of appr. 180 trains which are controlled by the train control system. Two train controllers handle the entire traffic load. One train controller is responsible for a $60 \mathrm{~km}$ line and the other train controller is responsible for two smaller lines with a combined length of $30 \mathrm{~km}$.

Each day appr. 50,000 data telegrams are sent between the central computer and the trains and are subsequently handled by the system. These data telegrams guarantee the correct and correlated real-time status at both the central computer and at each on-board computer. The rate of lost data telegrams is very low and in general is handled automatically. The rate of data integrity of the sent telegrams is $100 \%$. The accuracy of train location is precise and reliable, limited in turn by the accuracy (+/- $10 \mathrm{~m})$ of present day GPS positioning systems and the installed GPS receivers. The train control system is, however, designed to handle location errors up to the aforementioned threshold.

The operating personnel can handle the system easily because the operational sequences to which they are accustomed have remained unchanged. The system has led to an important advantage in the overall simplification of operation, providing the train controllers with a real time overview of the whole line and allowing them to supervise the safety and also the reliability of the time table 
very precisely. Furthermore, a lab simulator gives the train controllers the opportunity to train for abnormal and rare operating conditions.

The presented train control system has achieved its goals and demonstrates its abilities in daily operation.

\section{Conclusion}

The train control system presented in this paper represents a viable and low cost alternative for the automation of regional branch lines, using cab signalling, modern data radio communication, and computer based support for safety relevant actions. Due to the lack of line-side installations investment cost are very low when compared to different modes of standard signalling systems.

Field testing since 2006 has yielded excellent results in both reliability and operability. The personnel who have worked with the system are highly accepting of it. Moreover the system is comparably easy to install.

\section{References}

[1] Pachl, J., Railway Operation and Control, Mountlake Terrace WA: VTD Rail Publishing, ch. 1.4.2 and 3.5, 2002.

[2] Scheppan, M., Zugleitbetrieb für einfache betriebliche Verhältnisse, Eurialpress Teztlaff-Hestra, Hamburg, 2006

[3] EN 50128, Railway applications - Communications, signalling and processing systems - Software for railway control and protection systems, European Standard, 2001

[4] Stadlmann, B., Systematic UML-design used in the development of a basic train control system for regional branch lines, Proceedings of Symposium FORMS/FORMAT, eds. Schnider, G., Braunschweig, pp. 71-78, 2004

[5] Lehotzky, P., Befund und Gutachten über die eisenbahnbetriebstechnische Prüfung des rechnerunterstützten Zugleitsystems Stern \& Hafferl, unpublished, 2006 